$$
\text { CONF- } 9605173--13
$$

\title{
Initial Commissioning Results from the APS Loss Monitor System*
}

\author{
Donald R. Patterson
}

Advanced Photon Source, Argonne National Laboratory, Argonne, IL 60439
RECEIVED

AUG 121996

OSTI

\begin{abstract}
The design of the beam loss monitor system for the Argonne National Laboratory Advanced Photon Source is based on using a number of air dielectric coaxial cables as long ionization chambers. Results to date show that the loss monitor is useful in helping to determine the cause of injection losses and losses large enough to limit circulating currents in the storage ring to short lifetimes. Sensitivities ranging from 13 to $240 \mathrm{pC}$ of charge collected in the injector BTS (booster-to-storage-ring) loss monitor per picocoulomb of loss have been measured, depending on the loss location. These results have been used to predict that the storage ring loss monitor leakage current limit of $10 \mathrm{pA}$ per cable should allow detection of losses resulting in beam lifetimes of 100 hours or less with $100 \mathrm{~mA}$ stored beam. Significant DC bias levels associated with the presence of stored beam have been observed. These large bias levels are most likely caused by the loss monitor responding to hard $\mathrm{x}$-ray synchrotron radiation. No such response to synchrotron radiation was observed during earlier tests at SSRL. However, the loss monitor response to average stored beam current in APS has provided a reasonable alternative to the DC current transformer (DCCT) for measuring beam lifetimes.
\end{abstract}

\section{INTRODUCTION}

The APS loss monitor system provides a relative measurement of beam loss rates throughout the entire APS accelerator, from the linac gun through the storage ring. This is done by detecting the high energy photons given off by the accelerated particles as they collide with the vacuum chamber wall, residual gas molecules, or some other obstruction. The loss monitor system provides

\footnotetext{
* Work supported by the U. S. Department of Energy, Office of Basic Energy Sciences, under Contract No. W-31-109-ENG-38.
} 


\section{DISCLAIMER}

Portions of this document may be illegible in electronic image products. Images are produced from the best available original document. 
diagnostic information only. It does not provide an input to the personnel safety system or the machine protection system.

\section{SYSTEM DESCRIPTION}

The loss monitor system is based on using a 7/8-inch air dielectric coaxial cable as an ionization chamber. It is similar in many ways to loss monitor systems in use at Brookhaven (1) and SLAC (2). Five hundred volts DC is applied to the center conductor of the cable and the cable shield is grounded. An ionization gas consisting of a mixture of $95 \%$ argon and 5\% carbon dioxide at 8 psig is passed through the cable. The average current flowing from the center conductor through the ionization gas to the cable shield is measured and is proportional to the average beam loss rate along the cable. The system design is described in more detail elsewhere $(3,4,5)$.

The loss monitor cable is installed parallel to the vacuum chamber subject to the restrictions caused by mechanical interference with other equipment and the need for personnel movement and access to equipment. When possible, the cable was installed below the plane of the rings or inside the rings in an attempt to minimize exposure to synchrotron radiation. Air dielectric coaxial cables are placed along the entire length of each of the major machine components.

The current signals from the coaxial cable ionization chambers are multiplexed into one of nine electronics packages. Each electronics package can accept inputs from up to seven coaxial cables. Accelerator physics personnel determined the number and length of the coaxial cables used to cover the accelerator components, taking into account the need for spatial resolution and cost considerations. A total of 35 individual cables are multiplexed into the nine loss monitor electronics packages. The electronics packages include a DC-coupled current amplifier that measures the total ionization current flowing through the selected coaxial cable. Personnel safety considerations require that the cable shields be grounded and the high voltage be applied to the cable center conductor. This requires that the current amplifier be floating on top of the high voltage.

The loss monitor system is controlled by the EPICS-based (6) accelerator control system. Data can be presented to the operators and physicists numerically or graphically and can be recorded for later analysis and archival purposes using a series of software tools. 


\section{RESULTS}

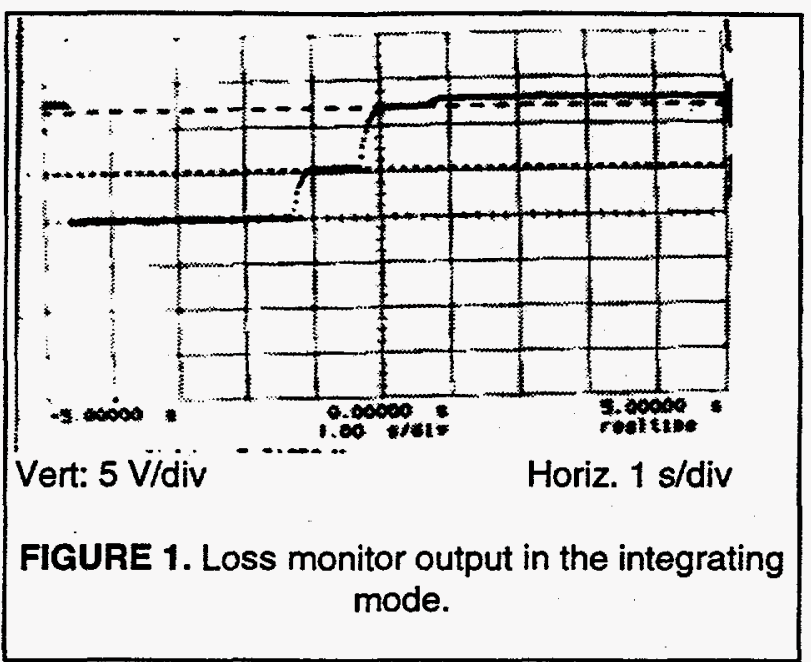
the two steps in the oscilloscope trace show the collection of the charge induced in the loss monitor cable from the loss of two $0.5-\mathrm{nC}$ bunches. The voltage step indicated by the cursors is 6.72 volts in amplitude, and corresponds to $6.72 \mathrm{nC}$ of collected charge, since the loss monitor electronics was in the $10-\mathrm{nC}$ range. This results in a sensitivity of about $13.5 \mathrm{pC}$ of charge collected from the loss monitor cable per picocoulomb of charge lost in the storage ring at $7 \mathrm{GeV}$ at this location.

A similar technique was used to measure sensitivities in the BTS, as shown in Figure 2. In this case, the location of a loss of $1.1 \mathrm{nC}$ at $7 \mathrm{GeV}$ was adjusted to eight different locations along the BTS. As shown in Table 1, the loss monitor sensitivity varies by more than a factor of 10 depending of the location of the loss. This is probably due to the fact that losses at some locations see relatively little

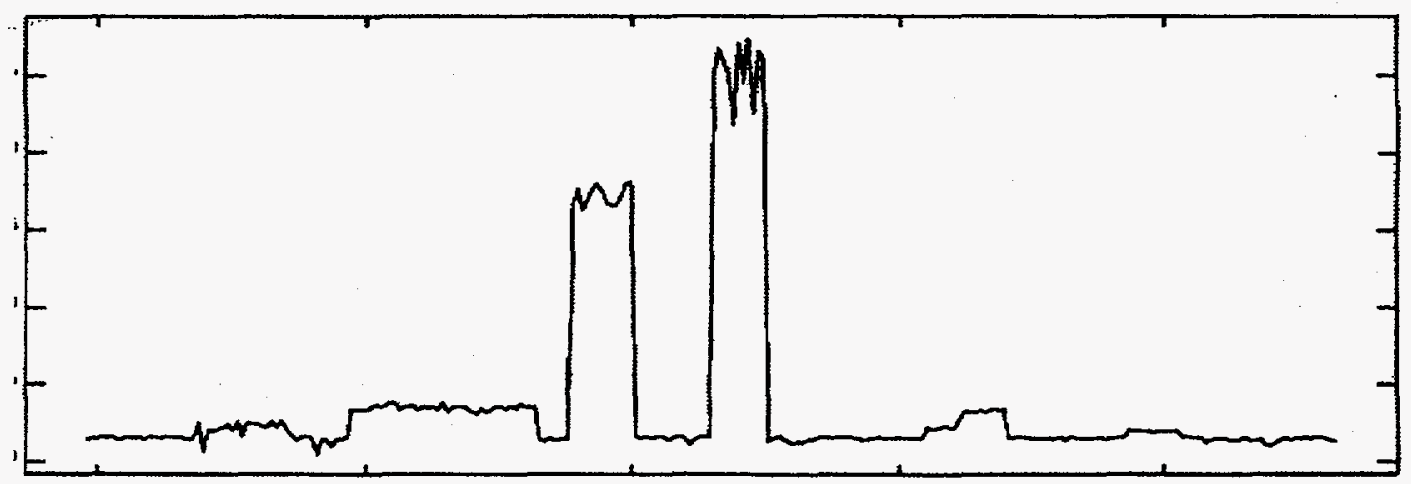

FIGURE 2. Loss amplitude as a function of location in the BTS. 
shielding (primarily the aluminum vacuum chamber wall) between the loss point and the loss monitor cable, while losses as other locations may see several feet of shielding (steel and copper in large magnets) between the loss point and the loss monitor cable. The conclusion is that the loss monitor reading should be only taken as a relative reading. The readings can be used to tune for minimum loss at one fixed location, but great caution should be exercised when using the loss monitor to compare the amplitudes of losses in different locations.

Table 1: Loss Monitor Sensitivities at Various Locations in the BTS

\begin{tabular}{|l|c|c|}
\hline \multicolumn{1}{|c|}{ Loss Location } & $\begin{array}{c}\text { Loss Monitor Reading, } \\
\boldsymbol{\mu C}\end{array}$ & $\begin{array}{c}\text { Calculated Sensitivity, pC } \\
\text { Collected per pC of Beam } \\
\text { Loss }\end{array}$ \\
\hline Thick Septum & 0.016 & 15 \\
\hline Thin Septum & 0.026 & 24 \\
\hline First Vertical Corrector & 0.036 & 33 \\
\hline Second Vertical Corrector & 0.166 & 150 \\
\hline Third Vertical Corrector & 0.26 & 240 \\
\hline First Horizontal Corrector & 0.022 & 20 \\
\hline First Flag & 0.020 & 18 \\
\hline Second Flag & 0.014 & 13 \\
\hline
\end{tabular}

Leakage currents in the loss monitor electronics, air dielectric coaxial cables, and signal lead-in cables determine the minimum collected charge that can be measured. Leakage currents in the storage ring are usually less than $10 \mathrm{pA}$. In the booster synchrotron tunnel, where temperature and humidity are uncontrolled during the summer, leakage currents can occasionally approach 100 pA but are usually below $10 \mathrm{pA}$. These leakage currents result in a minimum detectable charge of less than $5 \mathrm{pC}$ in the storage ring and $50 \mathrm{pC}$ in the booster for a $0.5-\mathrm{s}$ integration time. With measured sensitivities ranging from roughly 13 to $240 \mathrm{pC}$ collected per picocoulombs lost, beam current losses of 0.021 to $0.38 \mathrm{pC}$ are expected to be detectable in the storage ring and losses of 0.21 to $3.8 \mathrm{pC}$ or better are expected to be detectable in the booster and BTS (booster-to-storage-ring transport line), depending on location and humidity.

The expected sensitivities to losses with stored beam in the storage ring can also be calculated from the above measurements. With stored beam, the average beam current follows an exponential decay,

$$
I=I_{o} e^{-t / \tau}
$$

where $I$ is the DC circulating current in the storage ring as a function of time, $\mathrm{L}_{0}$ is the $\mathrm{DC}$ circulating current at time $\mathrm{t}=0$, and $\tau$ is the lifetime of the stored beam. 
If $Q_{c}$ is the circulating charge, $Q_{c o}$ is the circulating charge at time $t=0$, and $T$ is the time required for the charge to make one pass around the storage ring, then

$$
I=\frac{Q_{c}}{T}, \quad I_{o}=\frac{Q_{c o}}{T}, \quad \text { and } \quad Q_{c}=Q_{c o} e^{-t / \tau}
$$

Then

$$
\frac{d Q_{c}}{d t}=-\frac{Q_{c o}}{\tau} e^{-t / \tau}=-\frac{d Q_{L}}{d t}=-\frac{1}{k} \frac{d Q_{l m}}{d t},
$$

where $\mathrm{Q}_{\mathrm{L}}$ is the charge lost from the stored beam, $\mathrm{Q}_{\mathrm{lm}}$ is the charge collected by the loss monitor, and $\mathrm{k}$ is the sensitivity factor in $\mathrm{pC}$ of collected charge per $\mathrm{pC}$ of charge lost from the beam current. From this,

$$
\frac{I_{o} T e^{-t / \tau}}{\tau}=\frac{1}{k} \frac{d Q_{l m}}{d t}=\frac{1}{k} I_{l m},
$$

where $\mathrm{I}_{\mathrm{Im}}$ is the current collected by the loss monitor and

$$
I_{l m}=\frac{I_{o} T k e^{-t / \tau}}{\tau}=-\frac{d I}{d t} k T .
$$

Since the leakage currents in the storage ring are less than $10 \mathrm{pA}$ in each of the ten cables, a uniformly distributed loss that generates $10 \mathrm{pA}$ in each of the ten loss monitor cables for a total of $100 \mathrm{pA}$ should be detectable. Using Eq. (5) above with a charge revolution time $T$ of $3.68 \mu$ s and an effective $k$ value (averaged over all locations) of about 100 , losses in the storage ring associated with lifetimes in the range of $\tau=100$ hours or less with $\mathrm{I}_{0}=100 \mathrm{~mA}$ circulating beam should be detectable. However, actual measurements taken on April 3, 1996, with $20 \mathrm{~mA}$ of stored beam and 17 hours lifetime show loss monitor readings of about $1.1 \mu \mathrm{A}$ in each of the ten cables. These readings are about five orders of magnitude larger than expected from the above equations using the loss sensitivities obtained with single-bunch data. Apparently the loss monitors are responding to scattered synchrotron radiation despite the attempt to locate the cables below the plane of the storage ring. No such response to synchrotron radiation was observed during earlier tests at SSRL (3). This apparent response to synchrotron radiation makes the storage ring loss monitors of little value in measuring losses that may exist with reasonable beam lifetimes. 
It has been observed, however, that the loss monitor readings are proportional to beam current (see Figure 3). This has allowed the loss monitor signal to be used as a low-noise input signal for the calculation of beam lifetimes.

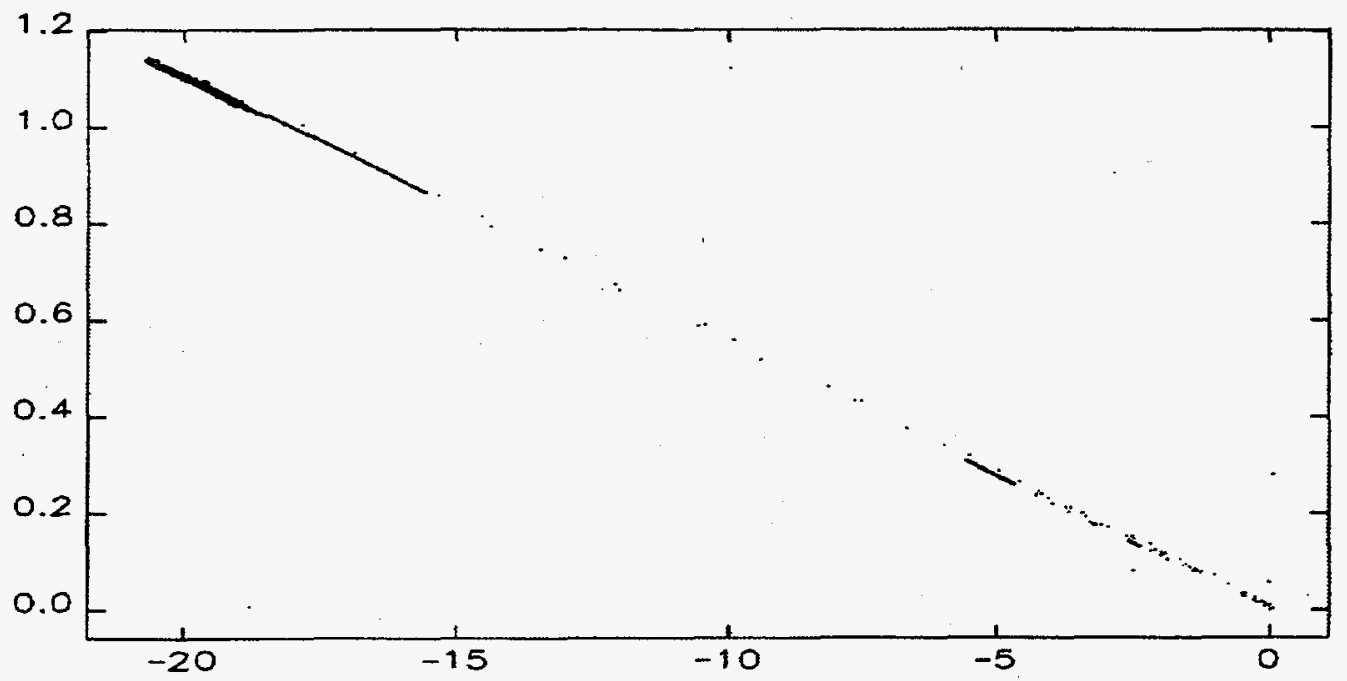

FIGURE 3. Loss monitor readout (vertical axis, $\mu \mathrm{A}$ ) versus beam current (horizontal axis, $\mathrm{mA})$.

The response of the loss monitor to beam obstructions can be further illustrated by observing the response of the booster-to-storage-ring loss monitor as the scrapers are inserted into the beam. Figure 4 shows the loss monitor signal as the second top and bottom scrapers in the BTS are inserted, then removed. The initial loss monitor signal is caused by the beam hitting the septum. The first peak in the signal is caused by the beam striking the edge of the top scraper. The first valley is the loss monitor signal caused by the beam striking the body of the top scraper. The second peak is again generated by the edge of the top scraper as it is withdrawn. The second valley is the loss monitor signal caused by the beam striking the bottom scraper. Note the lack of signal peaking as the bottom scraper grazes the beam. It appears that the beam strikes the edge of the top scraper as it grazes the beam and the resulting radiation shower is directed downward toward the loss monitor cable, resulting in a signal peak. Similarly, the beam strikes the edge of the bottom scraper as it grazes the beam and the resulting radiation shower is directed upwards away from the loss monitor cable, resulting in no loss monitor signal peak. 


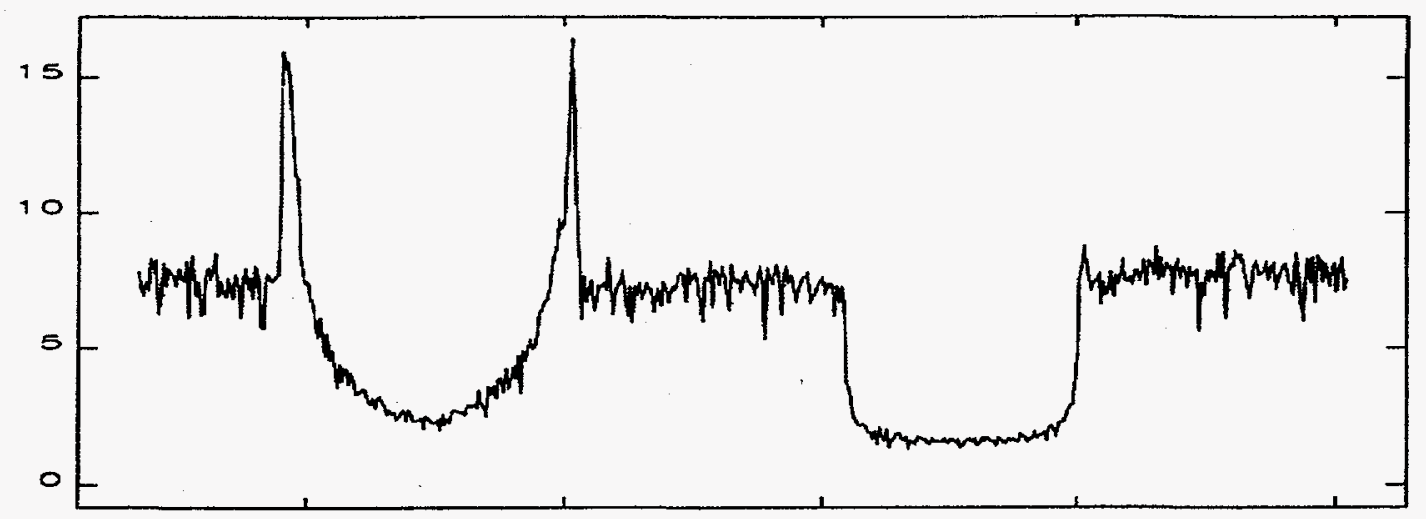

FIGURE 4. Loss monitor signal as scrapers are inserted into the beam.

\section{FURTHER WORK}

Further work is required to verify that the predominant loss monitor signal with stored beam is due to response to synchrotron radiation. It may be possible to partially shield the loss monitor cable by placing it inside a metal conduit so as to attenuate the softer synchrotron radiation while allowing the harder Bremsstrahlung radiation to pass into the loss monitor cable. It might also be possible to reduce the sensitivity to synchrotron radiation by relocating the loss monitor cable. However, this seems unlikely to be productive because of mechanical and access restrictions on the cable location and the likelihood that the synchrotron radiation is scattered sufficiently to almost uniformly bathe the storage ring tunnel.

The loss monitor electronics package has been designed to allow measurement of the voltage pulses that arise in the loss monitor cables from large, localized losses. Preliminary measurements indicate that it may be possible to measure the timing of these pulses relative to the beam timing to determine the location of the loss within a cable. The feasibility of automatically making these timing measurements will depend largely on the noise pickup in the cabling. This will be studied in more detail in the future. 


\section{REFERENCES}

1. Witkover, R. L, "Beam Instrumentation in the AGS Booster," Proceedings of the Third Annual Workshop on Accelerator Instrumentation, Newport News, VA, AIP Conf. Proc. 252, American Institute of Physics, NY, 188-202 (1991).

2. McCormick, D., "Fast Ion Chambers for SLC," Proceedings of the 1991 IEEE Particle Accelerator Conference, San Francisco, CA, 91CH3038-7, 1240-1242 (1991).

3. Patterson, D. R., "Design and Performance of the Beam Loss Monitor System for the Advanced Photon Source," Proceedings of the Beam Instrumentation Workshop, Vancouver, Canada, October 2-6, 1994, AIP Conference Proceedings 333, 300-306 (1995).

4. Patterson, D. R., "Preliminary Design of the Beam Loss Monitor System for the Advanced Photon Source," Proceedings of the Fourth Accelerator Instrumentation Workshop, LBL, Berkeley, CA, October 27-30, 1992, AIP Conference Proceedings No. 281, 150-157 (1993).

5. Lumpkin, A., Patterson, D., Wang, X., Kahana, E., Sellyey, W., Votaw, A., Yang, B., Fuja, R., Berg, W., Borland, M., Emery, L., Decker, G., and Milton, S., "Initial Diagnostics Commissioning Results for the Advanced Photon Source (APS)," Proceedings of the 1995 IEEE Particle Accelerator Conference, Dallas, Texas, May 1-5, 1995, 2473-2475 (1996).

6. Documentation available on the World Wide Web at http://www.aps.anl.gov /asd/controls/epics/EpicsDocumentation/WWWPages/EpicsFrames.html.

\section{DISCLAIMER}

This report was prepared as an account of work sponsored by an agency of the United States Government. Neither the United States Government nor any agency thereof, nor any of their employees, makes any warranty, express or implied, or assumes any legal liability or responsibility for the accuracy, completeness, or usefulness of any information, apparatus, product, or process disclosed, or represents that its use would not infringe privately owned rights. Reference herein to any specific commercial product, process, or service by trade name, trademark, manufacturer, or otherwise does not necessarily constitute or imply its endorsement, recommendation, or favoring by the United States Government or any agency thereof. The views and opinions of authors expressed herein do not necessarily state or reflect those of the United States Government or any agency thereof. 